\title{
Disaster Case Management and Individuals With Disabilities
}

\author{
Laura M. Stough and Amy N. Sharp \\ Texas A\&M University
}

\author{
Curt Decker and Nachama Wilker \\ National Disability Rights Network, Washington, DC
}

\begin{abstract}
Purpose: To examine the case management and disaster recovery needs of individuals with disabilities following Hurricane Katrina. The case managers and supervisors in this study provided case management to individuals with disabilities as part of the largest coordinated disaster case management program in U.S. history, the Katrina Aid Today consortium. This study provides an account of the disaster case management needs of individuals with disabilities as well as a picture of their long-term recovery process two years following the disaster. Design: Forty-two case managers and 12 case management supervisors from this program provided services to a collective caseload of 2,047 individuals with disabilities and their families. Interviews and telephone surveys were conducted with these participants $20-24$ months after the disaster. The qualitative data were analyzed using grounded theory methodology, and descriptive statistics summarize the demographic data. Results: Findings suggest that the disaster recovery process is typically more complex and lengthy for individuals with disabilities and requires negotiation of a service system sometimes unprepared for disability-related needs. Barriers to disaster recovery for individuals with disabilities included a lack of accessible housing, transportation, and disaster services. Supports to disaster recovery included the individual effort and advocacy of a case manager, connecting with needed resources, collaboration with other agencies, and client motivation and persistence. Implications: Results suggest that disaster recovery is facilitated by case managers with disability expertise, including knowledge about the needs of individuals with disabilities and about disability-related services.
\end{abstract}

Keywords: disability, case management, disasters

Case management is a practice used to connect individuals to needed resources and services such as housing, employment, and transportation. Case managers assess a client's service needs and then assist the client with information about and application to these services. The case management process is intended to be collaborative and includes "... assessment, planning, facilitation, care coordination, evaluation and advocacy for options and services ..." (Case Management Society of America, 2010, p. 8). Other functions of case management are to integrate and coordinate services across different service delivery systems and to provide for continuity of care on behalf of an individual or group

Laura M. Stough and Amy N. Sharp, Department of Educational Psychology and Center on Disability and Development, Texas A\&M University; and Curt Decker and Nachama Wilker, National Disability Rights Network, Washington, DC.

Aspects of this article were presented as a paper at the Galveston Brain Injury Conference, April 29-30, 2009 at Moody Gardens, Galveston, TX.

This study was supported, in part, by a grant to the Center on Disability and Development at Texas A\&M University, which was funded by the Association of University Centers on Disability and the National Disability Rights Network. The National Disability Rights Network received a case management grant from UMCOR and NVOAD, which was funded through FEMA. The opinions expressed in this article are those of the authors and do not necessarily reflect those of the above-named organizations. The authors gratefully acknowledge the contributions of J. Aaron Resch, Christina Knight, and Amy Heath to this research.

Correspondence concerning this article should be addressed to Laura M. Stough, PhD, Department of Educational Psychology, Mail Stop 4225, Texas A\&M University, College Station, TX 77840. E-mail: 1stough@tamu.edu of individuals (Moxley, 1989). Case management may also incorporate advocacy functions when case managers solicit agencies for services on the behalf of their clients (Compton, Galaway, \& Cournoyer, 2005). A common objective of case management is to provide cost-effective services while simultaneously striving to improve the client's quality of life (Hall, Carswell, Walsh, Huber, \& Jampoler, 2002). Research on case management has found mixed results with respect to its cost effectiveness (see Mueser, Bond, Drake, \& Resnick, 1998; Mullahy \& Jensen, 2004), but the bulk of the evidence suggests that case management leads to positive outcomes such as an increase in functional status or in quality of life (Gorey et al., 1998).

Case management practice has been described and enacted across a number of disciplines including social work, vocational rehabilitation, and mental health (Mueser et al., 1998; Rose \& Moore, 1995). Typically, one designated case manager is assigned to an individual or family. The case manager meets with clients to determine their current needs and to collaboratively agree on goals. The case manager informs clients about resources that might meet their needs and the programs for which they meet eligibility. At the same or subsequent meetings, the case manager identifies documentation needed to apply for assistance and guides the client in completing applications. Case managers keep their clients updated about the outcomes of their applications, alternative sources for assistance, and appointments clients may have as part of their search for services. When case managers serve individuals with disabilities, they hold the same role; however, they must also be knowledgeable about their clients' eligibility for disability-related services and their needs for disability-related supports. 


\section{Disaster Case Management}

Case management has been used in recent decades by disaster relief organizations such as the Red Cross and the United Methodist Committee on Relief (UMCOR) to provide management of resources, such as housing or employment, needed by individuals affected by disaster. Disaster case management differs in objective and timing from other types of case management in that it seeks to return the client to his or her predisaster status and is time limited in scope (Administration for Children and Families, 2009). As part of disaster case management, clients are usually eligible for temporary resources, such as emergency housing, and services, such as crisis counseling, not part of typical case management. A common tool in disaster case management is the development of a "recovery plan" in which the case manager and client jointly identify disaster-related needs and goals (Bell, 2008). The Post-Katrina Emergency Reform Act of 2006 amended the Homeland Security Act of 2002 and added case management services as part of disaster programs that can be funded by the federal government:

\footnotetext{
Similar to case management in other areas, disaster case management has as its goal to provide a timely assessment of client needs and setting agreed upon goals with their client. In disaster case management the types of resources needed, such as housing or home repair, as well as existing health and social service needs that may affect the recovery of an individual following disaster are assessed. (Federal Emergency Management Agency [FEMA], 2009, Section 426, p. 156)
}

As with other forms of case management, disaster case management is facilitated through a single point of contact, usually a designated case manager, to coordinate services that often are provided by a wide range of disaster response organizations. Disaster case managers may also advocate for disaster-related resources such as FEMA assistance and mental health counseling.

Historically, disaster case management in the United States has been provided through donated funds and primarily delivered by faith-based organizations, many of which are members of National Voluntary Organizations Active in Disaster (NVOAD). Until recently, the case management process was relatively unstructured and varied in delivery, given the voluntary organization. The Post-Katrina Emergency Management Reform Act of 2006 also authorized financial support for case management to private nonprofit organizations following major disasters. However, the reform act legislated that federal disaster services must respond to the needs of all disaster survivors, including those of people with disabilities.

\section{Disaster Context of Study}

Our study took place 20 months following the 2005 landfall of Hurricane Katrina. Hurricane Katrina resulted in loss or destruction of housing for more than 1.5 million individuals as well as the dispersion of hundreds of thousands of individuals to all 50 states of the union (Department of Homeland Security, 2009). Across the United States, it is estimated that more than $20 \%$ of the population, approximately 54 million, have a disability and that approximately $30 \%$ of the nation's 69.6 million families have at least one member with a disability (U.S. Census Bureau, 2006). Although estimates vary given the definition of disability used, the National Organization on Disability (NOD; 2005) reported that between $21.3 \%$ and
$27.1 \%$ of the population affected by Hurricane Katrina were individuals with a disability.

\section{The Katrina Aid Today Program}

The UMCOR and NVOAD were awarded an unprecedented \$66 million in October 2005 through the Department of Homeland Security to provide case management for evacuees affected by Hurricane Katrina. This initiative led to the formation of the National Case Management Consortium and the Katrina Aid Today (KAT) project to provide disaster case management services to more than 73,000 households affected by Hurricane Katrina. The KAT case management consortium included the participation of nine national disaster relief organizations, which were later joined by 16 grassroots disaster organizations. The KAT consortium used case management as the primary vehicle by which it supported the disaster recovery process (UMCOR, 2008). UMCOR developed professional case management materials and training for partner organizations that were part of this effort and provided administrative oversight for the program (NOD, 2009).

As part of the KAT project, the National Disability Rights Network (NDRN) specifically targeted individuals with disabilities and their families. NDRN is the nonprofit membership organization for the federally mandated Protection and Advocacy Systems for individuals with disabilities and through its network is the largest provider of legally based advocacy services to people with disabilities in the United States (NDRN, 2009). NDRN affiliates are located in each state. The NDRN state-affiliated organizations had considerable disability-related expertise and experience with legal advocacy on the behalf of individuals with disabilities, but disaster case management was a new role for these organizations. NDRN employed the Americans With Disabilities Act (ADA) definition of disability, which included individuals with "... a physical or mental impairment that substantially limits one or more of the major life activities of such individual; a record of such an impairment; or being regarded as having such an impairment" but, in practice, NDRN affiliates also accepted clients who self-defined as having a disability. The state-affiliated offices of NDRN delivered disaster case management, which was overseen by one or more case management supervisors. Other consortium members were informed about the expertise of NDRN-affiliated offices and could transfer their cases of families with disabilities to these caseworkers.

Disaster research on individuals with disabilities is limited and has focused on the experiences in the immediate aftermath of an event (e.g., Barile, Fitchten, Ferraro, \& Judd, 2006; Kaile, 2008; NOD, 2005). Research on the long-term recovery needs of individuals with disabilities has been even more limited. White, Fox, Rooney, and Cahill (2007) suggested that the disruption of medical and social support systems differentially affected individuals with disabilities one year after Hurricane Katrina. Christ and Christ (2006) found that teachers were particularly important supports for children with disabilities who had lost a family member following the 9/11 Twin Towers disaster. Individuals receiving disabilityrelated services were found to require case management for a longer length of time during the long-term recovery period and to be more likely to need housing or financial assistance (Stough \& Roberts-Gray, 2008). None of these studies, however, examined 
the in-depth experiences of case managers for individuals with disabilities.

The purpose of this study was to examine the case management and long-term recovery needs of individuals with disabilities affected by Hurricane Katrina. The case managers in this study were employed by NDRN as part of the KAT project, which began 6 months after Hurricane Katrina made landfall, as part of the largest coordinated disaster case management program in U.S. history.

\section{Method}

\section{Participants}

Case managers. Two groups of participants were used for data collection. The first group consisted of case managers at NDRN affiliate offices who provided direct support, such as locating resources and assisting with application for services, to individuals with disabilities. A total of 58 KAT case managers were employed by NDRN affiliates in the states of Louisiana, Mississippi, Alabama, Texas, and Georgia. These states were also the locations where the largest number of hurricane survivors relocated following Hurricane Katrina. Twenty-one months following the storm, $13(22.4 \%)$ of these case managers had already left their positions, and three $(9.5 \%)$ others were still employed but did not respond to repeated requests to participate. The sample therefore consisted of 42 case managers who were actively providing case management services.

Fourteen of the participating case managers were employed in Mississippi, 12 in Louisiana, four in Alabama, nine in Texas, and three in Georgia. Of the case managers surveyed, $83 \%$ were women and $17 \%$ were men; $47 \%$ were African American and 53\% European American. Thirty-six percent were single, 50\% married, $14 \%$ separated or divorced. Sixty-five percent had a bachelor's degree, $23 \%$ had a master's degree, $6 \%$ had some college, $3 \%$ had a doctoral degree, and $3 \%$ of the respondents had a law degree. Sixty-two percent of these case managers were working in an area damaged by the storm and $64 \%$ also considered themselves to be survivors of the storm. These case managers had provided case management to Katrina survivors for an average of 10.2 months, with a range of 2 to 18 months in their current positions. Prior to their employment with KAT, these case managers had an average of 3 years of experience in another case management position, with $86 \%$ reporting that they had at least 1 year of paid experience with individuals with disabilities. All of these case managers had received training in disaster case management through the KAT consortium and oversight from a case management supervisor with expertise in disability issues.

A total of 2,047 families, all of whom were survivors of Hurricane Katrina, collectively represented the caseload of these case managers. The types of disabilities included in these caseloads ranged from those that were more common, such as intellectual disabilities and mobility impairments, to low-incidence disabilities, such as blindness and traumatic brain injury. The average number of current cases per case manager was 48 ; however, one case manager reported a high of 240 cases, and another case manager reported a low of seven cases. Some of the KAT programs were closing and clients had been reassigned, which accounted for the discrepancy in these caseloads. All of the case managers surveyed worked full time and handled cases of individuals with disabilities exclusively. Of the total cases managed by these case managers, 1,046 (51\%) had been resolved and closed at the time of this study, with a high of 100 closed cases for one case manager and a low of zero for another.

Case management supervisors. The second participant group consisted of the 12 supervisors of the above-described case managers. These supervisors were responsible for the administration of the case management program and, in five cases, were also responsible for the overall administration of the NDRN affiliate office. Three administrators at the national level were also interviewed regarding the overall management of the project, but these data were not incorporated into this study. ${ }^{1}$ All supervisors had continuous feedback from their case managers and, in most instances, the supervisors occasionally provided direct case management. All 12 case management supervisors had been with the program from its inception in their state, and all but three had been employed by their NDRN affiliate office before the KAT case management program had begun.

Of the 12 supervisors interviewed, three were employed in Mississippi, four in Louisiana, three in Texas, and two in Georgia. Ten were women and two were men; one was African American, two were Hispanic, and remaining nine were ethnically European American. Two of the interviewed supervisors were single, nine married, and one divorced. Four supervisors had a bachelor's degree, four a master's degree, and the remaining four had a law degree.

\section{Design and Procedure}

Surveys of case managers. Case management supervisors distributed a letter from the investigators about the survey to the case managers and encouraged them to participate. The investigators then contacted each case manager via e-mail or telephone to set up an appointment to administer the survey. Each case manager was contacted at least three times in an attempt to set an appointment at a time that was convenient to them.

The telephone surveys were administered and collected by the first two authors over a 6-week period beginning 20 months after the storm. These surveys included structured interview questions and the survey procedure was consistent across all case managers The interview questions were developed through a rigorous piloting procedure by researchers working with two other KAT consortium partners (see Bell, 2008) that used focus groups, interviews, and informal discussions to inform the development of the questions. These questions were then piloted with case managers and used as part of an evaluation study conducted by Lein, Bell, Beausoleil, Montez, and Borah (2007). These investigators then provided feedback and guidance on the use of these questions for the current study, following a parallel protocol to that used by Lein et al.

All case managers were administered the same 12 demographic questions and nine interview questions. The survey began with

\footnotetext{
${ }^{1}$ These administrators were responsible for the oversight and administration of the NDRN KAT project at the national level rather than providing direct oversight of case managers. As their responses might readily reveal their identities, these data were not included in the analysis.
} 
demographic questions (e.g., job title, years of experience, education level) followed by the series of open-ended interview questions. Case managers were asked to describe the biggest challenges they felt clients faced, the factors that supported successful disaster recovery, how disability affected the provision of case management services, and the importance of disability-related knowledge. In addition, the interviewers used a critical incident technique (see Flanagan, 1954) for two of the interview questions. Critical incident technique is used to interview participants within a workplace or organizational setting and focuses on specific instances that have occurred rather than using direct questions. In our questions, case managers were asked to describe one particular case they believed was successful, as well as one case that was particularly challenging. Follow-up probes were used to obtain more detail about factors that were attributed to these specific cases. The telephone survey took an average of 25 minutes to complete.

Interviews with supervisors. Semistructured face-to-face interviews were conducted with the 12 case management supervisors 23 to 24 months following the storm and 2 months after initial coding had been completed on the survey data collected from the case managers. A face-to-face interview procedure was selected to provide in-depth investigation of the themes that emerged from the analyzed telephone surveys. The interview format also elicited contextual data about the complex resource and administrative factors that affected the delivery of case management in the program.

Five interview questions were asked of each supervisor, and follow-up probes were used to elicit more specific or elaborative information as needed. The questions focused on the challenges and affordances of providing case management to individuals with disabilities. Specifically, case managers were interviewed about their organization's case management services, their partner organizations in the disaster case management consortium, and the role of disability-related knowledge in providing effective disaster case management. All 12 interviews were conducted face-to-face at the supervisors' offices, with the exception of one, which was completed by telephone because of an unexpected scheduling conflict. Follow-up questions to elicit clarification and elaboration were asked following each question. Field notes were made by a second researcher to document the context of the interview, gestures, voice inflections, and areas of focus during each interview. Each interview lasted from 25 to 50 minutes. All interviews were audiotaped, and these audiotapes were transcribed for further analysis.

\section{Analysis}

Grounded theory methodology (Charmaz, 2006; Corbin \& Strauss, 2008) was used to analyze the data. Grounded theory is a particularly appropriate method to use when the area of interest has not been previously investigated, such as this examination of the disaster case management. Grounded theory is also an appropriate methodology to use when a theoretical framework does not exist for the study of a phenomenon. Our choice was to follow recent examples of grounded theory methodologies (e.g., Charmaz, 2006; Corbin \& Strauss, 2008) rather than traditional grounded theory (e.g., Glaser, 2000; Glaser \& Strauss, 1967) as we viewed this study as breaking initial theoretical groundwork rather than theory building. Our analytical objective was to develop categories of commonality across the case managers, to describe the relationship between these categories, and to develop a substantive (initial) description of the disaster-related needs of individuals with disabilities.

Our beliefs admittedly shaped the design and the interpretation of the data. The first two authors analyzed the data from the telephone interviews and the face-to-face interviews. Both authors were disability researchers and espoused a social constructivist view of disability. In this view, disability is seen as residing in the interactions between society and an individual, rather than representing individual pathology. All four authors held the belief that individuals with disabilities had rights to equal access to services and resources as well as to equal treatment under the law. The data and emergent themes were always considered against the backdrop of larger social, economic, and political factors that affect the participation of individuals with disabilities in current U.S. life.

Coding was completed on the telephone surveys before beginning the face-to-face interviews with the case management supervisors. The telephone surveys were analyzed using line-by-line coding of the responses to each open-ended question. First-pass data analysis was performed using open coding (Corbin \& Strauss, 2008; Glaser \& Strauss, 1967), in which the transcripts were analyzed using a line-by-line approach. As the analysis proceeded, these codes were grouped to form categories. In forming these categories, the constant comparative method (Glaser \& Strauss, 1967) was used to systematically compare the responses of each additional participant to the categories that were obtained from analyzing previous participants. This methodology allows for the comparison of new datum to previous cases so that the new information permits the researcher to iteratively gain more precise information on the category of analysis. The second author opencoded the transcripts from the surveys. The first author audited the open coding by reading each thought unit identified by the second author and checking it against the code used. A total of 802 thought units were analyzed from the 54 transcripts. After all transcripts from the telephone surveys had been open coded, these open codes were collapsed into overarching categories.

The first-pass analysis of the case manager data was followed by interviews with the case management supervisors. The transcripts from these interviews were coded using the categories obtained from the analysis of the surveys, rather than by using emergent open coding. Data from the case manager supervisors did not result in the formation of new categories, confirming that our categories derived from the case manager data had reached saturation. The process of using preexisting categories to guide our coding of the supervisor process also allowed us to elaborate the categories and further refine their properties and dimensions. A researcher who had assisted with the data collection, but who had not assisted with the coding of the data, was used as an auditor to check the validity of the description of each category. The categorization process was accompanied by axial coding, wherein these categories were conceptually related to each other (Corbin \& Strauss, 2008). In our axial coding process, we examined the properties of the categories to assist us in determining to what extent and how these categories were related.

Selective coding is one of three types of coding commonly used in grounded theory (Strauss \& Corbin, 1990). During our selective coding of these data, the categories were conceptually arranged around a core category. In this study, the core category or phe- 
nomenon was "the recovery process for individuals with disabilities postdisaster." This theme was determined to be related to all of the categories derived from the analysis, but was particularly strongly related to the actions and strategies that the case managers collectively employed on behalf of their clients. Other categories generated from the analysis were then conceptually placed in relationship to this central category and examined for how they led to "successful recovery from the disaster." To document this process, the researchers used memos and a research journal to document meetings, descriptions, and conclusions about the data. These materials provided an audit trail of the analysis process. The third and fourth authors read the descriptions of the categories and provided feedback on the interpretations of these themes. In sum, these qualitative analyses produced (a) categorization of the results, (b) a description of the properties and dimensions of each category, (c) text summaries of each category of interest, (d) quotes that exemplified and elaborated on each category, and (e) a storyline of how the resulting categories interacted and affected each other. Demographic information elicited from the telephone surveys was tallied, and descriptive statistics were calculated for the responses that could be quantified.

\section{Results}

The purpose of this study was to examine the long-term recovery status of individuals 2 years following disaster. In the following section, we report on the five categories that contained properties most directly related to disability issues rather than attempting to present all of the categories derived from our analysis. Direct quotes, as well as summarized responses, are presented to substantiate and illustrate these five thematic categories. Firstlevel analysis concept labels have been italicized under each category. Our interpretation of these categories has been integrated with the presentation of the results.

\section{Role of Disability in Disaster Case Management}

Most of the case managers in this study had past experience as case managers of clients without disabilities. The case managers and the case management supervisors, as part of their role in the KAT consortium, communicated frequently with case managers in other organizations. Eighty-three percent of the 42 case managers, and all of the supervisors, agreed that disaster case management for people with disabilities differed from case management with people without disabilities. The participants reported that people with disabilities required qualitatively different case management practices that were more intense, of longer duration, and that included more frequent contacts with the client. Case management that was needed by clients with disabilities was referred to as "holistic" or "deep case management" and was used in response to the multiplicity of their service needs. The complexity of these needs required disability expertise to be able to locate needed supports. As the case management needs were more intensive and time consuming, fewer cases could then be feasibly managed by each individual case manager, necessitating a smaller caseload. As one case manager explained,

It is like driving a standard versus an automatic. They both go straight, and turn and back up. But to accomplish that [to drive a standard] you have to have a little more involvement and a little more knowledge. I can depend on [a person without disabilities] to return papers to me and call me back and follow up. A person with cognitive disability or physical disability may need more support and for me to come face to face for the job to get done. There is some difficulty involved in it. There are differences in cases between the two sectors. Not necessarily harder but a bit more involved. ${ }^{2}(\mathrm{CM} 45)^{3}$

The case management supervisors concurred that individuals with disabilities had preexisting circumstances that made recovery more difficult for individuals with disabilities. Supervisors had access to statistical data provided through the KAT consortium that documented demographic difference for the clients with disabilities and referred to these data in their interviews. For example, as a group, individuals with disabilities participating in the KAT program were less likely to be homeowners. This meant that some of the FEMA homeowner programs were not of use to them or, in the case of FEMA trailers, were not accessible to them. Individuals with disabilities were also less likely to be employed, and this affected their ability to pay utility bills or purchase furniture when they did transition to more permanent housing. Individuals with disabilities were more likely to have medical needs, which affected their ability to travel to service agencies or obtain employment. Case management with the survivors with disabilities was seen as taking longer in part because of the need for these multiple areas of support. A case manager summarized,

I think that our clients bring a lot less [tangible efforts] to the table to contribute. At the LTRC [Long-Term Recovery Committees] tables when asked "What have they come with? What have they done for themselves?" They come with a lot less. You have to look a lot harder to get the resources that they need, you have to be a lot more creative with donations and volunteer labor. (CM7)

Accessing available resources was a concern expressed often throughout the interviews: "Being disabled you are limited to when and where you can go so if you aren't there at a particular time you miss out" (CM6). Case managers believed that part of their job was to assist their clients with disabilities in accessing these services.

For evacuees that were displaced accommodations, such as doctors and in-home care, that had been part of the individual's life predisaster, were needed. These accommodations were challenging to reassemble as they had been designed for singular and individualized needs. Case managers noted that some accommodations that were in place before the storm might no longer function in the new environment and that it took time to reassemble these accommodations:

When you have been living in a place and the natural supports disappear, to put that back into place it does became very expensive. If equipment got lost, some is covered by insurance, some is not, and to replace things costs. Those kinds of things are expensive for people. Also some of the things that worked previously in your old home do not work in the new

\footnotetext{
${ }^{2}$ Throughout this article, consistent effort is made to respect the voice and expression of the participants. As a result, quotes in this report may appear ungrammatical or to have syntax errors. Quotes are only edited to increase readability.

${ }^{3}$ Following participant quotes, "CM" denotes a case manager and "CMS" denotes a case management supervisor. The participant number follows this code.
} 
environment, for example, you have to retrain guide dogs. Some things simply don't travel well. (CMS15)

People with disabilities were seen as more reliant on public services such as public transportation and social services, and public infrastructure was seen as being particularly important to individuals with disabilities for them to recover from disaster:

Getting connected back to the support systems is difficult. Sometimes their supports is their extended family and they have been moved many times. From that aspect it has been much harder for people with disabilities. Even the home health agencies have fewer staff to support people [returning to the disaster area]. It takes people with disabilities longer to return to independent living. (CMS10)

A related category was that survivors needed an extended time for recovery from the disaster: "The length of time has been the biggest variable, in hindsight" (CMS13). Part of this extended time for recovery was linked to the need for the existing public infrastructure to be rebuilt or modified as an essential part of the supports for people with disabilities. For example, for individuals with visual impairments, the public transportation system was an essential support that needed to be in place before they could effectively mobilize within the city:

The length of time for cases with people with disabilities is much longer because the needs are more involved. If someone is on SSDI [Social Security Disability Income], they do not have the capability to support themselves without additional support .... When a person has needs that involve support needs, for example, nursing or employment support, it takes longer. (CMS11)

\section{Supports to Recovery}

Case managers were asked to describe an exemplar successful case and to identify the factors that they believed contributed to the successful resolution of the case. The supervisors were asked more generally about the factors that they believed contributed to successful case management. Many of the open codes about supports to client recovery came from the responses to these questions and were collapsed during data analysis to form the following categories.

Most participants described how the efforts of the case manager contributed to the recovery of their clients, particularly with regard to their effectiveness of collaborating with other agencies. These comments detailed how they had connected their client to appropriate resources, most particularly housing, FEMA benefits, and financial support. Many of their reports included examples of how they advocated for these resources on behalf of their clients:

To be fair the resources that have been made available to me through training and networking partners ... coupled with my own tenacity and propensity for continuing to advocate for a client. Resources are there it just took digging and work for a successful end result. (CM46)

Case managers also focused persistently on the importance of connecting clients to needed resources. Case managers described successful cases as those in which a case manager successfully brokered a connection between the client's needs and concrete, valued resources:

I assisted a client to get her water turned on. I did major leg work to get the paperwork and got it to the necessary people. I linked her to a resource that paid her bill in full and they turned it on in minutes. The success is the resources being available and me being able to tap into them for her. (CM11)

Everything just came together. It had to do with the particular needs of the clients and what I could offer. These clients just needed furniture but had already obtained their own mobile home. They are older and disabled. What their needs were and what I could provide matched up. (CM8)

When case managers were able to facilitate these connections, they saw themselves as providing positive supports to the recovery of their clients from the disaster. Thus, the cases most likely seen as "successful" were often those in which the case manager's actions had also been successful.

Key to the success of the case management efforts of these participants was collaboration with case managers from other agencies:

I helped a client with cerebral palsy get out of her trailer before she got evicted and got her into accessible housing. It took a teamwork of coworkers, me knowing the right people at the housing authority—all of these factors came together to help. (CM28)

The importance of collaboration was echoed by case management supervisors who described forming new connections at the organizational level:

We had effective collaborations before the storm but now we have whole new partners. We wouldn't have targeted some of these agencies for collaboration before, for example, Catholic Charities, but now our agencies know about each other and work together. (CMS12)

Case managers mentioned that the motivation and persistence of their clients played a large role in how successful they were in accessing resources for them:

A family who is in the process of finding permanent housing applied for a HUD home and they got it but it was in Georgia, so we assisted them in moving. The case was successful because they were satisfied with where they were going. The mom was very resourceful and proactive and would work on her own behalf in making contacts with agencies. (CM53)

Another case manager discussed a client who lived independently before Katrina but who was put in a nursing home after the storm: "He did not want to be in a nursing home and was very motivated to live on his own. His motivation made it much easier for me to help him achieve his goal to live on his own" (CM23). One case manager made the wry comment, "It helps when the client is more interested in their recovery than you are" (CM4) and described a client who demonstrated persistence in that he followed up on tasks, was patient, and gave the case manager the necessary paperwork required to get the additional funding and services that he needed.

The category of motivation and persistence does not seem any different from those that would be present in the successful resolution of cases of individuals without disabilities. Seeking disaster services requires persistence in learning a new service system that is unfamiliar, as well as skills sets that are not accessible for individuals with particular types of disabilities. For example, with individuals with cognitive disabilities, the functions of providing paperwork, navigating the service system, and initiating contacts with service agencies may need to be explained and supported more intensively by the case manager. For individuals with communicational disabilities, again, the assistance of a case manager in communicating with outside agencies and understanding informa- 
tion may be critical roles for the case manager. Persistence may have been mentioned frequently by the case managers in this study because it was a strategy needed to compensate for the additional barriers experienced by individuals with disabilities.

\section{Barriers to Recovery}

Several distinct factors were consistently identified by the case managers as barriers to successfully recovering from the storm. The case managers interviewed perceived the single biggest challenge faced by their clients to be housing:

Housing, housing and housing ... they face so many challenges. Clients who were living in low-income housing find that there is none left now. Even finding an apartment is difficult. (CM2)

The need for housing was not unique to individuals with disabilities; it was also the primary need of other Hurricane Katrina survivors (UMCOR, 2008) following the disaster. However, these case managers reported that their clients often had disabilityrelated needs that further complicated the process of locating permanent housing:

I have a client and her son is paralyzed and in a wheelchair. They lost their home, were in a FEMA trailer, the trailer had a fire, and the mom got severely burned. They were left homeless. Mom was in hospital recovering from burns, the son went to live with distant relatives where the conditions were deplorable. We were able to find temporary housing and now they are in more permanent housing. What made it successful was that we pulled together and collaborated. They were rightly owed a housing subsidy by FEMA so we advocated for that. (CM32)

Another significant challenge reported by disaster survivors was the need for transportation. A case manager pointed out that "Clients were used to public transportation. They became stranded because they no longer had that public transportation" (CM 34). Clients from New Orleans previously had access to a range of public transportation, including buses, taxis, and ferries, as well as transportation provided by family members and informal shared rides. As most of the survivors had been displaced, some of these informal transportation supports were no longer available:

Not being able to find what they are looking for. One person needed to move to another location and really did not have any transportation to find somewhere to live or a way to get a moving truck or someone to help her move. (CM37)

Case managers and supervisors gave multiple examples of difficulties that people with disabilities had in working through the disaster service system:

A young man was in a nursing home and needed to be moved to another city; however, Medicare won't pay for it because he isn't going to hospital but to a home to be closer to his family, which they do not consider to be a medical necessity. FEMA says it has been too long after the hurricane for them to assist him. The ambulance service is willing to cut their costs to transport him but we still don't have the means to pay $\$ 800$ to move him. He is medically fragile and cannot be moved by other means. (CM10)

Case management supervisors commented on the barriers encountered at a systemic level in which their clients had to navigate not only the disaster resource system but simultaneously navigate the disability service system:
On top of the types of support that people need when they are recovering from an emergency event, people with disabilities need even more. Knowing how to navigate in those service systems is critical. Their support needs need to be met in a timely fashion and need to be appropriate-if not, harm can be caused such as putting people with medical needs at high risk or neglect issues can occur. On average, people with disabilities have a lower level of income, are more likely to rely on Medicaid, and so forth. If you are a case manager that has been working in public health or with non-Medicaid populations, disability services are a different service arena to be knowledgeable about. In the KAT situation this situation was greatly exaggerated. We had people who crossed state lines and we had to figure out how to keep in place services like attendant care, which were paid for by one state while they were receiving disaster relief services in another. It was difficult to keep the services uninterrupted. They needed case managers who could coordinate across all systems. (CMS15)

The barrier of working through these services systems was seen by these participants as best mitigated through the strategy of having a caseworker with disability-related expertise.

\section{Disability-Related Expertise of Case Managers}

Disability expertise was another "action/interaction strategy" (see Corbin \& Strauss, 2008) that appeared to contribute positively to the successful recovery of the client. The respondents overwhelmingly agreed that knowledge of disability and knowledge of disability services were required to provide effective case management to evacuees with disabilities:

A person with disabilities has to navigate within the typical system so a typical case manager cannot imagine if it is already hard for a nondisabled person to navigate a typical environment, it is enhanced when you have a disability. There is so much more to deal with. (CM61)

The respondents believed that case managers who had knowledge of disability services would be more successful than case managers who did not. Essential to the success of these case managers was understanding disability services and eligibility for services, and not having this knowledge was perceived as a barrier. In some cases, the respondents stressed that the nature of the support that was needed from the case manager was actually more pertinent than the preexisting condition of the individual:

Somewhere along the way if they don't plug into some agency that can address their needs, they will miss out on services that they are entitled to and need. Case managers need to have some knowledge of what is available for people with disabilities, but it doesn't mean that the part of the recovery that is difficult depends on their disability. I think it is because the case manager needs to know what services are out there for people with disabilities. (CM53)

Finally, it was reported that caseworkers needed to be able to aware of the attitudes and biases that society has against individuals with disabilities and be prepared to deal with negative attitudes when seeking resources for their clients:

... disability is an added barrier to an already difficult-to-navigate system. You add in cognitive issues, language, and mobility barriers, such as HUD doesn't have an elevator to their office, so how is he [a person with a disability] going to get up there? Many people with cognitive disabilities can't even articulate their needs. (CM29) 


\section{Influence of Disability Specialists on Disaster Case Management Practice}

When asked whether the disability-related expertise of the NDRN-affiliated case managers had influenced other disaster case management in other agencies, $86 \%$ of the case managers responded affirmatively. The NDRN-affiliated case managers believed that their expertise was recognized by the other disaster case management agencies. The disability case managers in this study thus saw themselves as shaping the overall context of the KAT consortium, while simultaneously working within the case management system.

The majority of the respondents believed that their involvement in KAT would make other organizations more prepared to serve survivors with disabilities in future disasters. Sharing the goal of assisting hurricane recovery survivors also helped form new collaborations with other agencies and organizations. For example, one supervisor shared,

I think that overall it has pointed out to each of us what the other does. After this, we may be a little closer and we may be able to work together better. Our KAT has had an effect on the partners because ours [the relationship] has been so dynamic. (CMS9)

In many cases, the NDRN affiliates took leadership among the KAT partners in hosting meetings at their offices, holding workshops on best practices in case management, or providing training and information on working with individuals with disabilities. Conversely, the NDRN affiliates had the opportunity to serve clients with characteristics that they had not previously served, for example, elderly people with functional limitations but who did not consider themselves as having a disability. Case managers and supervisors alike believed that individuals with disabilities in the community became more aware of the legal advocacy services offered by NDRN affiliates due to the expanded role that NDRN played in the recovery process.

Statements regarding impact on partner agencies usually focused on the disability awareness that the partner agencies now had about the needs of individuals with disabilities:

An agency did not understand the needs of the clients and made statements that were very judgmental about the client's situation. This agency has judged the client and made it difficult for them to receive services. FEMA was not aware of the client's needs, especially the client's needs that had to do with the client's disability status. I worked to help FEMA understand the client's situation. (CM3)

However, most respondents were somewhat unsure about the extent to which their organizations had influenced case management practice in the KAT project, and it was hard for them to identify concrete evidence of their impact on their partner agencies. Most respondents believed that they had yet to see the direct results of their advocacy efforts. Although case managers felt they provided much disability-related information and referral services to their partner agencies, they felt their impact was one of disability awareness rather than a change in practice. Other case managers were likely to call the NDRN affiliate when they needed disability-related information, but it was unclear to the participants whether these interactions changed practice. Participants also wondered whether cases should be simply transferred to case managers who might be better equipped to assist clients with disabilities. Many case managers believed that their ability to navigate in the disability arena allowed them to advocate more successfully for their clients. One case manager conceptualized this expertise as a service that her organization brought to other agencies: "It makes their job easier because we are doing the footwork for people with disabilities" (CM5). Participants believed that presence of case managers and supervisors with expertise on disability issues at the "disaster recovery table" did make their partners think about disability issues in ways they had not done previously. However, respondents were uncertain whether this increase in disability awareness would change how case management services would be delivered in the future.

More definitive change was seen as part of the legal actions that the NDRN affiliates took on behalf of their clients. In their role as a protection and advocacy agency, the affiliates were well versed in issues regarding accessibility of services and provision of information in accessible format to clients with disabilities. In some cases, supervisors informed other agencies about the legal rights of individuals with disabilities and the need to make case management accessible and user-friendly for all clients. One participant commented, "Case managers typically know about social services but didn't learn about disability accommodation. So we have been able to share the legal rights of people with disabilities, have made them more aware" (CMS7). All of the case managers believed that they had influenced the other partners to at least think about the rights of individuals with disabilities.

\section{Discussion}

Reports from the disaster case managers and their supervisors in this study suggest that considerable barriers continued to exist for their clients with disabilities 20 months after Hurricane Katrina. Many of the needs reported, such as for housing and transportation, mirror reports from individuals without disabilities recovering from disaster (see Lein et al., 2007), and the case managers in this study saw their role as critically supportive of their clients with disabilities. Collectively, they illustrate a complex picture of disaster case management for individuals with disabilities. These disaster case managers did not portray the disabilities of their clients as being, in and of themselves, barriers, but that disaster recovery was more difficult to obtain for individuals with disabilities given how disaster recovery services were configured. Thus, when a client had a disability such as traumatic brain injury or an intellectual disability, negotiating a challenging service labyrinth was further complicated. Disaster case management from someone with disability expertise was seen as necessary support for negotiating barriers to recovery, as these case managers could interpret, translate, advocate, and understand the needs of the client in a manner that someone without disability-related expertise might not. Furthermore, disaster case managers and supervisory personnel believed they had the potential to create awareness across agencies and increase the likelihood that disability accommodations might be adopted by other agencies in the future.

With regard to long-term recovery, the reported needs of individuals with disabilities unfortunately echo reports on other survivors of Hurricane Katrina (see Lein, 2007; UMCOR, 2008). These disaster survivors continued to need housing, employment, transportation, financial, and other resources 2 years following the disaster-and many of these resources had dissipated since the initial aftermath of the storm. This dwindling of resources further 
challenged these disaster case managers in connecting their clients to needed resources and services. As one case manager explained,

This is the disaster they can't recover from. The disaster is the unnavigable system. You can't develop a recovery plan for people who are still in a disaster. The trauma is till happening. There are no supports, no systemic supports. We change the rules of the game every day. They can't recover until they have some stability of support around them. The supports are not here yet and there is no norm. They need the basic survival needs in place. The disaster is still happening. The indifference of the system has been another disaster. (CM30)

Findings from these case managers have been echoed by researchers, advocacy groups, and policymakers. Several empirical articles (Lishner, Richardson, Levine, \& Patrick, 2008; Manders \& Stoneman, 2003) found a strong need for even experienced case managers to receive disability-related training. The NOD (2009) called for case management processes that were responsive to the needs of individuals with disabilities: "Those with expertise and experience in case management, including people with disabilities and disability organizations, should be hired to manage the cases" (p. 322). A recent U.S. House of Representatives (2009) hearing "Looking Out for the Very Young, the Elderly and Others With Special Needs: Lessons From Katrina and Other Major Disasters" identified case management as a central component in the needs of individuals with disabilities recovering from disaster. Finally, a July 2009 report to Congress titled "Greater Coordination and an Evaluation of Programs' Outcomes Could Improve Disaster Case Management" pointed out that case management agencies experienced considerable challenges post-Katrina because of limited community resources and large caseloads. The U.S. Government Accountability Office (2009) recommended that further research and evaluation studies were needed on disaster case management outcomes to more effectively design future case management programs.

The Stafford Disaster Relief and Emergency Assistance Act authorized case management as a part of the National Response Plan in 2006. As a result, case management will be used more frequently postdisaster and with a wider range of disaster survivors. Guidelines that address the case management needs of people with disabilities have been incorporated into the national case management implementation guide released by the Administration for Children and Families (2009) and incorporate a similar case management structure as described in this study. However, disaster case management, particularly of individuals with disabilities, has received little attention from researchers. Careful study of the needs of individuals with disabilities and their families during the long-term recovery phase following disaster is an essential step in improving the recovery outcomes of this population.

Results of this study provide an initial examination of the role of disability in disaster case management. Findings are limited in that no direct comparison was made to case managers of individuals without disabilities (although a parallel study was completed by Lein et al. in 2007). In addition, the case managers in this study consisted solely of individuals who were part of the KAT program. Because of case management attrition, the entire population of case managers from NDRN affiliates was not interviewed as some were no longer employed at the time of this study. In addition, the telephone surveys and interviews took place 20-24 months after the beginning of the case management program. A longitudinal approach, in which case managers were interviewed at several points in time during the program, would have made the design of the study stronger. Finally, although these case managers had detailed information about their clients' needs and frequent contact with them, the experience of disaster recovery was not examined directly from the perspective of the clients themselves.

Very little evidence-based research focuses on the experience of individuals with disabilities following disaster. This article reports one of the few systematic studies on the long-term recovery needs of individuals with disabilities through reports from their disaster case managers. Future research that incorporates the voices of individuals with disabilities will provide a clearer illustration of the extent to which disaster service programs can effectively address multiple support needs following disaster.

\section{References}

Administration for Children and Families. (2009, November). Disaster case management: Implementation guide. Washington, DC: U.S. Department of Health and Human Services. Retrieved from http://www.acf.hhs.gov/ ohsepr/dcm/docs/Draft_DCM_ImplementationGuide.pdf

Barile, M., Fichten, C., Ferraro, V., \& Judd, D. (2006). Ice storm experiences of persons with disabilities: Knowledge is safety. The Review of Disability Studies, 2, 35-48.

Bell, H. (2008). Case management and displaced survivors of Hurricane Katrina: A case study of one host community. Journal of Social Science Research, 34, 15-27.

Case Management Society of America. (2010). Standards of practice for case management. Little Rock, AR: Author. Retrieved from http:// www.cmsa.org/portals/0/pdf/memberonly/StandardsOfPractice.pdf

Charmaz, K. (2006). Constructing grounded theory: A practical guide. Thousand Oaks, CA: Sage.

Christ, G. H., \& Christ, T. W. (2006). Academic and behavioral reactions of children with disabilities to the loss of a firefighter father: The New York World Trade Center attack 9/11/01. The Review of Disability Studies, 2, 68-77.

Compton, B., Galaway, B., \& Cournoyer, B. (2005). Social work processes (7th ed.). Belmont, CA: Brooks/Cole-Thomson Learning.

Corbin, J., \& Strauss, A. (2008). Qualitative research: Techniques and procedures for developing grounded theory (3rd ed.). Thousand Oaks, CA: Sage.

Federal Emergency Management Agency. (2009). National disaster housing strategy, Annex 2: Methods to house disaster victims. Washington, DC: U.S. Department of Homeland Security. Retrieved from http:// www.fema.gov/pdf/emergency/disasterhousing/NDHSAnnex2.pdf

Flanagan, J. C. (1954). The critical incident technique. Psychological Bulletin, 51, 327-359.

Glaser, B. G. (2000). The discovery of grounded theory. Mill Valley, CA: Sociology Press.

Glaser, B. G., \& Strauss, A. (1967). The discovery of grounded theory. Strategies for qualitative research. Chicago: Aldine.

Gorey, K. M., Leslie, D. R., Morris, T., Carruthers, W. V., John, L., \& Chacko, J. (1998). Effectiveness of case management with severely and persistently mentally ill people. Community Mental Health Journal, 34, 241-250.

Hall, J. A., Carswell, C., Walsh, E., Huber, D. L., \& Jampoler, J. S. (2002). Iowa case management: Innovative social casework. Social Work, 47, 132-141.

Kaile, J. (2008). Southern California wildfires after action report. Pomona, CA: Access to Readiness Coalition, The California Foundation for Independent Living Centers, and The Center for Disability Issues and the Health Professions at Western University of Health Sciences. Retrieved from http://www.jik.com/CaliforniaWildfires.pdf

Lein, L., Angel, R., Bell, H., \& Beausoleil, J. (2007). The state and civil 
society response to disaster: The challenge of coordination. Organization and Environment, 22, 448-457.

Lein, L., Bell, H., Beausoleil, J., Montez, J. K., \& Borah, E. V. (2007). Mid-term evaluation. Katrina Aid Today case management program. Unpublished evaluation report. Retrieved from www.utexas.edu/research/ cswr/katrina/Documents/070914\%20KAT\%20Report.pdf

Lishner, D. M., Richardson, M., Levine, P., \& Patrick, D. (2003). Access to primary health care among persons with disabilities in rural areas: A summary of the literature. Journal of Rural Health, 12, 45-53.

Manders, J. E., \& Stoneman, Z. (2003). Children with disabilities in the child protective services system: An analog study of investigation and case management. Child Abuse \& Neglect, 33, 229-237.

Moxley, D. P. (1989). The practice of case management. Newbury Park, CA: Sage.

Mueser, K. T., Bond, G. R., Drake, R. E., \& Resnick, S. G. (1998). Models of community care for severe mental illness: A review of the research on case management. Schizophrenia Bulletin, 24, 37-74.

Mullahy, C. M., \& Jensen, D. K. (2004). The case manager's handbook (3rd ed.). Boston: Jones \& Bartlett.

National Disability Rights Network. (2009). About us. Retrieved from http://www.napas.org/aboutus/default.htm

National Organization on Disability. (2005). Report on Special Needs Assessment for Katrina Evacuees (SNAKE) project. Washington, DC: Author. Retrieved from http://www.nod.org/Resources/PDFs/katrina_snake_report .pdf

National Organization on Disability. (2009, August). Effective emergency management: Making improvement for communities and people with disabilities. Washington, DC: Author. Retrieved from http://www.ncd .gov/newsroom/publications/2009/NCD_EmergencyManagement_HTML/ EffectiveEmergencyManagement.html

Post-Katrina Emergency Management Reform Act. (2006). Title VIIINational Emergency Management, Sec. 801. Retrieved from http:// www.nlihc.org/doc/080906.pdf

Rose, S. M., \& Moore, V. L. (1995). Case management. In R. L. Edwards
\& J. G. Hopps (Eds.), Encyclopedia of social work (19th ed., pp 335-340). Washington, DC: NASW Press.

Stough, L. M., \& Roberts-Gray, C. (2008). A quantitative evaluation of the National Disability Rights Network participation in the Katrina Today project. Washington, DC: The National Disability Rights Network.

Strauss, A., \& Corbin, J. (1990). Grounded theory research: Procedures, canons, and evaluative criteria. Qualitative Sociology, 13, 3-21.

U.S. Census Bureau. (2006). 2006 American community survey data. Washington, DC: Author. Retrieved from http://www.census.gov

U.S. Department of Homeland Security. (2009). The first year after Hurricane Katrina: What the federal government did. Retrieved from http:// www.dhs.gov/xfoia/archives/gc_1157649340100.shtm

U.S. Government Accountability Office. (2009, July). Disaster assistance: Greater coordination and an evaluation of programs' outcomes could improve disaster case management (Report No. GAO-09-561). Washington, DC: U.S. Government Printing Office.

U.S. House of Representatives. (2009, October). Committee on Transportation and Infrastructure. Hearing on "Looking Out for the Very Young, the Elderly and Others With Special Needs: Lessons From Katrina and Other Major Disasters." Retrieved from http://transportation.house.gov/ Media/file/Economic\%20Development/20091020/SSM_ED.pdf

United Methodist Committee on Relief. (2008). Katrina Aid Today: A national case management consortium. Final evaluation summary. New York: Author.

White, G. W., Fox, M. H., Rooney, C., \& Cahill, A. (2007). Assessing the impact of Hurricane Katrina on persons with disabilities. Lawrence: The University of Kansas, The Research and Training Center on Independent Living. Retrieved from http://www.rtcil.org/products/ NIDRR_FinalKatrinaReport.pdf

Received November 27, 2009

Revision received May 4, 2010 Accepted May 5, 2010

\section{E-Mail Notification of Your Latest Issue Online!}

Would you like to know when the next issue of your favorite APA journal will be available online? This service is now available to you. Sign up at http://notify.apa.org/ and you will be notified by e-mail when issues of interest to you become available! 